\title{
The complexity of care in amyotrophic lateral sclerosis
}

Geraldine Foley, BSc.OT, MSc.OT

National ALS Clinic, Beaumont Hospital, Ireland

Published in Amyotrophic Lateral Sclerosis, 2011, 12(3), 160-161

DOI: $10.3109 / 17482968.2011 .554556$ 


\section{Dear Sir}

Positive outcomes for ALS service users are key factors in determining the success of ALS health care services. As the disease progresses, people with ALS frequently shift their focus from health issues to supportive relations (1). The degree of functional impairment may have little impact on what is considered to be meaningful and important.

Users and providers of palliative services can hold different perspectives on the benefits of care (2) and outcomes for palliative service users are often determined by preferences for care, and not necessarily by care providers' intentions regarding care (3). Hence, attention to care preferences for people with ALS is essential in order to achieve better outcomes in ALS care.

People with ALS access services to relieve burden of care. While some may be resigned to the inevitability of ALS, service users may still have positive perceptions about health (4) and seek multidisciplinary intervention to meet physical, emotional and social needs (5). Physical disability alone may have little effect on service users' preference for care (6). Rather, a combination of optimism (7) and support (8) may determine the decisions they make about care. Preferences for care may also change over time (9) in order to accommodate to support systems and evolving perspectives on living with ALS (10).

A process of negotiation between accepting the inevitability of ALS and maintaining quality of life has been identified among ALS service users (11). Living with ALS may involve 'abruption' and 'disruption' but it also involves coping with loss through finding new meaning in life and exerting control. This adaptive response is characterized by a cyclical 
decision making process that seeks to preserve a sense of self and well-being in the face of adversity (12).

It is possible that the role of health care services in the lives of people with ALS has different meanings, depending on whether the service is delivered or received. While people with ALS seek and have expectations of a broad range of services, they also shift in their own expectations of life. As the disease progresses, services that provide psychological and social support may have a greater importance for service users than services which focus on physical disability alone. Health care professionals may not experience the same sort of shift. Despite the fact that people with ALS change in how they view their lives, no studies have focused specifically on how services should be delivered in order to match their shifting expectations of care.

ALS care is complex because service users exert control and independence as they negotiate between acceptance of ALS and desire to maintain quality of life. This poses many challenges for service providers as they must remain cognisant of the required negotiation between acceptance and independence while participating in the decision-making process about care.

Declaration of interest: The author declares no conflict of interest.

\section{References}

1. Fegg MJ, Kogler M, Brandstatter M, Anneser JR, Haarmann-Doetkotte S, Wasner $\mathrm{M}$, Borasio D. Meaning in life in patients with amyotrophic lateral sclerosis. Amyotroph Lateral Scler. 2010;11:469-474.

2. Rodriguez KL, Young AJ. Patients' and healthcare providers' understanding of lifesustaining treatment: are perceptions of goals shared or divergent? Soc Sci Med. 2006;62: 125-133. 
3. Normand C. Measuring outcomes in palliative care: limitations of QALYs and the road to PaIYs. J Pain Symptom Manage. 2009;38:27-31.

4. Young JM, McNicoll P. Against all odds: positive life experiences of people with advanced amyotrophic lateral sclerosis. Health Soc Work. 1998;23:35-43.

5. Hughes RA, Sinha A, Higginson I, Down K, Leigh PN. Living with motor neuron disease: lives, experiences of services and suggestions for change. Health Soc Care Community. 2005;13:64-74.

6. Munroe CA, Sirdofsky, Kuru T, Anderson ED. End-of-life decision making in 42 patients with amyotrophic lateral sclerosis. Respir Care. 2007;52:996-999.

7. Rabkin JG, Albert SM, Tider T, del Bene ML, O'Sullivan I, Rowland LP, Mitsumoto H. Predictors and course of elective long-term mechanical ventilation: a prospective study of ALS patients. Amyotroph Lateral Scler. 2006;7:86-95.

8. Albert SM, Whitaker A, Rabkin JG, del Bene M, Tider T, O'Sullivan, Mitsumoto H. Medical and supportive care among people with ALS in the months before death or tracheostomy. J Pain Symptom Manage. 2009;38:546-553.

9. Albert SM, Murphy PL, del Bene ML, Rowland LP. A prospective study of preferences and actual treatment choices in ALS. Neurology. 1999;53:278-283.

10. Fegg MJ, Wasner M, Neudert C, Borasio GD. Personal values and individual quality of life in palliative care patients. J Pain Symptom Manage. 2005;30:154-159.

11. Locock L, Ziebland S, Dumelow C. Biographical disruption and repair in the context of motor neuron disease. Socio Health Illn. 2009;31:1043-1058.

12. King SJ, Duke MM, O'Connor BA. Living with amyotrophic lateral sclerosis/motor neuron disease (ALS/MND): decision-making about 'ongoing change and adaptation'. J Clin Nurs. 2009;18:745-754. 